\title{
Comparison between intramuscular and intravenous regimen of magnesium sulfate in management of severe preeclampsia and eclampsia
}

\author{
Vaibhav Kanti ${ }^{1 *}$, Abhilasha Gupta ${ }^{2}$, Shikha Seth ${ }^{1}$, Mona Bajaj ${ }^{3}$, \\ Sunil Kumar ${ }^{4}$, Mukeshvir Singh ${ }^{5}$
}

\author{
${ }^{1}$ Department of Obstetrics \& Gynaecology, UPRIMS \& R, Saifai, Etawah, U.P., India \\ ${ }^{2}$ Department of Obstetrics \& Gynaecology, LLRM Medical College, U.P., India \\ ${ }^{3}$ Department of Obstetrics \& Gynaecology, Era Medical College, U.P., India \\ ${ }^{4}$ Department of Orthopedics, UPRIMS \& R, Saifai, Etawah, U.P., India \\ ${ }^{5}$ Department of Pediatrics , UPRIMS\&R ,Saifai,Etawah,U.P.,India
}

Received: 20 December 2014

Accepted: 11 January 2015

\author{
*Correspondence: \\ Dr. Vaibhav Kanti, \\ E-mail: vaibkanti13@gmail.com
}

Copyright: (C) the author(s), publisher and licensee Medip Academy. This is an open-access article distributed under the terms of the Creative Commons Attribution Non-Commercial License, which permits unrestricted non-commercial use, distribution, and reproduction in any medium, provided the original work is properly cited.

\begin{abstract}
Background: Objective of current study was to compare between intramuscular (IM) and intravenous (IV) magnesium sulfate regimen in terms of efficacy, side effects, maternal and fetal outcome.

Methods: A prospective study was performed on 82 patients from September 2008 to January 2010 and comparison was made between IV and IM group, each group consisting of 17 patients of eclampsia and 24 patients of severe preeclampsia. IV group received continuous IV magnesium sulfate (IV $\mathrm{MgSO}_{4}$ ) consisting of 4gm of loading dose, administered over 15 minutes followed by maintenance dose of $2 \mathrm{gm} /$ hour. The IM group received intramuscular magnesium sulfate $\left(\mathrm{IM} \mathrm{MgSO}_{4}\right)$ according to Pritchard regimen.

Results: Recurrence of convulsion in was found in $1 / 17$ (5.88\%) of eclamptic patients in IV and $1 / 17$ (5.88\%) in IM group which is statistically not significant $(\mathrm{P}=1)$. There was no occurrence of convulsion in any of the cases having severe eclampsia in either group. There was statistically no significant difference in maternal death between the two groups $(\mathrm{IM}=1 / 41(2.43 \%)$ and no mortality in IV group, $\mathrm{P}=0.314)$. Statistically higher incidence $(\mathrm{P}=0.034)$ of sign of impending toxicity such as loss of patellar reflex was seen in IM group as compared to IV group. Other signs of toxicity such as oliguria, respiratory rate depression though more in IM group, were statistically insignificant. There were no significant differences in other measures of serious maternal morbidity, in perinatal morbidity or mortality.

Conclusions: Both the groups are comparable in terms of control and prevention of recurrence of convulsions, maternal and perinatal morbidity and mortality.
\end{abstract}

Keywords: Eclampsia, Severe preeclampsia, IV, IM, Magnesium sulfate

\section{INTRODUCTION}

Eclampsia and preeclampsia are important causes of morbidity and mortality during child birth and puerperium. Eclampsia alone accounts for approximately
50000 maternal deaths worldwide annually. ${ }^{1}$ Incidence of eclampsia is one in 2000 deliveries in developed countries and one in 50 to 500 deliveries in developing countries. $^{2}$ The WHO notes that high blood pressure during pregnancy (preeclampsia and eclampsia) was one of the major direct cause of maternal deaths globally and 
its contribution in 2014 was $14 \% .^{3}$ Hypertension and its complications are the third leading cause of pregnancyrelated deaths, superseded only by hemorrhage and associated with increased risks of placental abruption, acute renal failure, cerebrovascular and cardiovascular complications, disseminated intravascular coagulation, and maternal death. ${ }^{4}$ In many developing countries like ours, particularly in rural areas; eclampsia may present for treatment in deep coma after many fits at home. Amongst the principles of management of eclampsia the first and the foremost is the control of convulsions. The results of collaborative eclampsia trial suggested that magnesium sulfate $\left(\mathrm{MgSO}_{4}\right)$ is the drug of choice for routine anticonvulsant management of women with eclampsia rather than diazepam and phenytoin. ${ }^{5}$ The major breakthrough in the management of eclampsia came when Dr. J. A. Pritchard published his standardized treatment protocol in 1984. His protocol for management is popularly known as 'Pritchard regimen' ${ }^{6}$ Zuspan and Sibai Baha both have proposed protocol which consists of continuous infusion of magnesium sulfate in which toxicity caused due to $\mathrm{MgSO}_{4}$ can be kept under control and complications due to toxicity could be prevented. Ekele BA, Badung SL in 2002 concluded that the routine estimation of magnesium cation is not necessary. It is suggested that serum estimation be limited to cases where clinical monitors suggest toxicity. ${ }^{7}$ Most of the health centers in world administer $\mathrm{MgSO}_{4}$ by continuous IV infusion because the IV route for $\mathrm{MgSO}_{4}$ administration has some advantage over IM $\mathrm{MgSO}_{4}$ in terms of easy administration, less painful to patient and mean magnesium level can be easily controlled but in India most medical centers prefer IM administration as described by Pritchard because in poor resource sets ups giving IV magnesium sulfate is not practical due to nonavailability of infusion sets, too busy nursing staff, taking sample for serum magnesium level at frequent interval is not cost effective. This encouraged us to do a study where both the route for $\mathrm{MgSO}_{4}$ administration were compared and magnesium toxicity was measured by clinical parameters so that an institutional study might help the primary and other referral units to use $\mathrm{MgSO}_{4}$ without any fear and delay.

\section{METHODS}

The study was conducted in Lala Lajpat Rai medical college, Meerut .This hospital is a tertiary referral centre and serves an indigent population from poor socioeconomic conditions. The primary aim of the study was to compare both the groups in terms of prevention of occurrence of convulsion in case of severe preeclampsia and recurrence of convulsion in case of eclampsia and other maternal complications.

The secondary outcome measures for this study were - To compare maternal and perinatal outcomes in between the two groups. Maternal outcome include - mode of delivery. Perinatal outcomes include - APGAR score, birth weight, perinatal mortality and rate of neonatal care unit admission. Inclusion criteria included women with severe proteinuric hypertension where decision had been made to deliver or was 24 hours or less postpartum and where any one of following criteria was met: 1 . Premonitory symptoms like headache, visual disturbance, persistent epigastric pain, oliguria or abnormal biochemical findings: platelet count $<100 \times 10^{9}$, ALT $>50$ IU/L, markedly increased creatinine $>2 \mathrm{mg} / \mathrm{dl}$. 2. Severe hypertension $(160 / 110 \mathrm{mmHg})$ with proteinuria of at least $2+$ assessed by semi quantitative dipstick method. 3 . Eclampsia: Eclampsia was diagnosed by taking history of generalized tonic clonic convulsions with or without elevated blood pressure and proteinuria (by dipstick method) in the absence of any underlying seizure disorders after 20 weeks of gestational age. All cases of antepartum, intrapartum and postpartum eclampsia, presenting in obstetric emergency (labour room) were included in the study. Patient with severe preeclampsia or eclampsia who had renal failure, severe pulmonary edema with respiratory failure, or hydatiform mole, diabetes mellitus, thyrotoxicosis, epilepsy, having received magnesium sulfate and/or other anticonvulsant before coming to our hospital, cerebrovascular accident and Disseminated Intravascular Coagulation (DIC) were excluded from the study. The patients enrolled were classified into two groups.

IM and IV group each having 41 patients (17 of eclampsia \& 24 of severe preeclampsia)

IV group received IV continuous infusion of $4 \mathrm{gm} \mathrm{MgSO}_{4}$ in $100 \mathrm{ml}$ Ringer lactate given within 20 minutes followed by maintenance dose $2 \mathrm{gm} /$ hour by infusion pump. IM group was given intra muscular magnesium sulfate according to Pritchard regimen - 4gm 20\% IV $\mathrm{MgSO}_{4}$ and $10 \mathrm{gm} \mathrm{IM} \mathrm{(5gm} \mathrm{in} \mathrm{each} \mathrm{buttocks)} \mathrm{as} \mathrm{loading}$ dose followed by maintenance dose of $5 \mathrm{gm} \mathrm{IM}$ magnesium sulfate in alternate buttock every 4 hours. In both groups $\mathrm{MgSO}_{4}$ was given till 24 hours after delivery or 24 hours after the last fit which ever was later. In both the groups if convulsions occurred within four hours after the loading dose then it was said to be recurrence of convulsions and additional dose of $2 \mathrm{gm}$ IV slowly magnesium sulfate was given and previous dose schedule were continued. Each case was monitored before giving each maintenance dose, for any evidence of magnesium toxicity, by observing knee jerk reflex, urinary output and respiratory rate. By patient's condition other clinical parameters were checked and guidelines for management of eclampsia were followed. Maintenance doses were deferred if knee jerk reflex was absent, or urine output $<100 \mathrm{ml}$ in 4 hours or respiratory rate $<16 / \mathrm{min}$. In all cases detailed history regarding high Blood Pressure (BP) recordings and medications taken, headache, blurring of vision, epigastric pain, number of convulsions, history of preeclampsia/eclampsia in previous and present pregnancy were noted. General physical examination included assessing patient's vital signs, blood pressure recording, pallor, edema, cyanosis and systemic examination included respiratory, cardiovascular and 
neurological examination. Obstetrical, pelvic examination and bishop scoring was done. Laboratory investigations done were blood group and $\mathrm{Rh}$ type, hemogram, platelet count, liver function tests, kidney function tests, serum electrolytes, coagulation profile and fundus examination and urine examination for protein. After stabilization of the patient, induction or augmentation of labor was done in all cases of antepartum and intrapartum eclampsia. If diastolic BP was higher than $110 \mathrm{mmHg}$, oral nifidipine $10 \mathrm{mg}$ in case of severe preeclampsia and sublingual nifidipine in case of eclampsia was used. Cesarean section was performed for obstetrical indication. Birth weight of the baby, APGAR score and neonatal outcome were recorded. Serum magnesium level could not be measured because it was not cost-effective.

\section{Statistics}

A comparative analysis was made between the two groups. Data were analysed using Statistical Package for
Social Sciences (SPSS) version 15.0, all the nonparametric data (proportional data) has been shown as number and percentages, parametric data as mean and standard deviation. Intergroup differences have been calculated using Pearson's Chi square test for proportions and independent sample's " $t$ " test or student " $t$ " for parametric data. The confidence limit of the study was kept at $95 \%$, a $\mathrm{P}$ value $\leq 0.05$ was taken as a level of statistically significant difference.

\section{RESULTS}

There were total 2739 deliveries in the hospital during the study period. The incidence of eclampsia in our hospital was 1.24 and of severe preeclampsia was $1.75 \%$. Such high incidence is due to referral from periphery as ours is a tertiary care centre. Patient characteristics and study parameters are presented in Table 1.

Table 1: Demographic and physical characteristic.

\begin{tabular}{|c|c|c|c|c|c|c|c|c|c|c|c|c|c|c|}
\hline \multirow{3}{*}{ Characteristic } & \multicolumn{6}{|c|}{ IM group ( $(\mathrm{n}=41)$} & \multicolumn{6}{|c|}{ IV group $(n=41)$} & \multicolumn{2}{|c|}{$\begin{array}{l}\text { Chi-square \& P } \\
\text { value (Control } \\
\text { vs. study group) }\end{array}$} \\
\hline & \multicolumn{2}{|c|}{$E(n=17)$} & \multicolumn{2}{|c|}{$\begin{array}{l}\text { SPE } \\
(n=24)\end{array}$} & \multicolumn{2}{|c|}{$\begin{array}{l}\text { Total } \\
(\mathrm{n}=41)\end{array}$} & \multicolumn{2}{|c|}{$E(n=17)$} & \multicolumn{2}{|c|}{$\begin{array}{l}\text { SPE } \\
(n=24)\end{array}$} & \multicolumn{2}{|c|}{$\begin{array}{l}\text { Total } \\
(\mathrm{n}=41)\end{array}$} & \multirow[t]{2}{*}{$\chi^{2}$} & \multirow[t]{2}{*}{$\mathbf{P}$} \\
\hline & No. & $\%$ & No. & $\%$ & No. & $\%$ & No. & $\%$ & No. & $\%$ & No. & $\%$ & & \\
\hline \multicolumn{15}{|l|}{ Religion } \\
\hline Hindu & 8 & 47.1 & 14 & 58.3 & 22 & 53.7 & 10 & 58.8 & 10 & 41.7 & 20 & 48.8 & \multirow{3}{*}{1.326} & \multirow{3}{*}{0.515} \\
\hline Muslim & 9 & 52.9 & 9 & 37.5 & 18 & 43.9 & 7 & 41.2 & 14 & 58.3 & 21 & 51.2 & & \\
\hline Others & 0 & 0.0 & 1 & 4.2 & 1 & 2.4 & 0 & 0.0 & 0 & 0.0 & 0 & 0.0 & & \\
\hline \multicolumn{15}{|l|}{ Rural/urban } \\
\hline Rural & 14 & 82.4 & 22 & 91.7 & 36 & 87.8 & 15 & 88.2 & 18 & 75.0 & 33 & 80.5 & \multirow{2}{*}{0.823} & \multirow{2}{*}{0.364} \\
\hline Urban & 3 & 17.6 & 2 & 8.3 & 5 & 12.2 & 2 & 11.8 & 6 & 25.0 & 8 & 19.5 & & \\
\hline \multicolumn{15}{|l|}{ Booked/unbooked } \\
\hline Booked & 3 & 17.6 & 2 & 8.3 & 5 & 12.2 & 1 & 5.9 & 6 & 25.0 & 7 & 17.1 & \multirow{2}{*}{0.390} & \multirow{2}{*}{0.532} \\
\hline Un-booked & & 82.4 & 22 & 91.7 & 36 & 87.8 & 16 & 94.1 & 18 & 75.0 & 34 & 82.9 & & \\
\hline Age $($ Mean \pm SD) $($ years $)$ & \multicolumn{2}{|c|}{$26.3 \pm 3.22$} & \multicolumn{2}{|c|}{$25.3 \pm 4.86$} & \multicolumn{2}{|c|}{$25.7 \pm 4.24$} & \multicolumn{2}{|c|}{$25.5 \pm 3.61$} & \multicolumn{2}{|c|}{$26.0 \pm 3.86$} & \multicolumn{2}{|c|}{$25.8 \pm 3.72$} & $\mathrm{t}=0.083$ & 0.934 \\
\hline BMI $\left(\right.$ Mean \pm SD) $\left(\mathrm{kg} / \mathrm{m}^{2}\right)$ & \multirow{2}{*}{\multicolumn{2}{|c|}{$23.2 \pm 1.77$}} & \multicolumn{2}{|c|}{$21.9 \pm 1.52$} & 22.5 & 1.74 & 24.5 & 3.80 & 22.3 & 2.78 & 23.2 & 3.38 & $\mathrm{t}=1.267$ & 0.209 \\
\hline Weight (Mean \pm SD)(kg) & & & 50.2 & 4.11 & 51.4 & 4.46 & 54.9 & 7.12 & 50.6 & 3.94 & 52.4 & 5.81 & $\mathrm{t}=0.851$ & 0.397 \\
\hline Parity & & & & & & & & & & & & & & \\
\hline Nulliparous & & & $24 / 4$ & & 58.5 & & & & $26 / 4$ & & 63.4 & & 0.205 & 0.651 \\
\hline Multiparous & & & $17 / 4$ & & 41.5 & & & & $15 / 4$ & & 36.6 & & & \\
\hline GA (weeks) $($ Mean \pm SD $)$ & & & & & 35.4 & 3.07 & & & & & 36.0 & 3.00 & $\mathrm{t}=0.878$ & 0.383 \\
\hline APE & 16 & & & & 94.1 & & 1 & & & & 82.3 & & & \\
\hline PPE & 1 & & & & 5.88 & & 3 & & & & 17.6 & & & \\
\hline $\begin{array}{l}\text { Admission-delivery time } \\
\text { interval }\end{array}$ & $\begin{array}{l}12.2 \\
\text { hour }\end{array}$ & & $\begin{array}{l}15.2 \\
\text { hou }\end{array}$ & & & & $\begin{array}{l}11.6 \\
\text { hour }\end{array}$ & & $\begin{array}{l}14.5 \\
\text { hour }\end{array}$ & & & & & \\
\hline Systolic BP & & & & & $\begin{array}{l}174 . \\
\mathrm{mm}\end{array}$ & $\begin{array}{l} \pm \pm 12.97 \\
\mathrm{Hg}\end{array}$ & & & & & $\begin{array}{l}173.2 \\
1 \mathrm{mn}\end{array}$ & $\begin{array}{l}2 \pm 14.8 \\
\text { of } \mathrm{Hg}\end{array}$ & 0.397 & 0.693 \\
\hline Diastolic BP & & & & & $\begin{array}{l}110.5 \\
\mathrm{~mm}\end{array}$ & $\begin{array}{l} \pm \pm 10.48 \\
\mathrm{Hg}\end{array}$ & & & & & $\begin{array}{l}110.2 \\
\mathrm{~mm}\end{array}$ & $\begin{array}{l} \pm \pm 7.58 \\
\mathrm{fHg}\end{array}$ & 0.362 & 0.718 \\
\hline
\end{tabular}

$\mathrm{GA}=$ Gestational age, $\mathrm{APE}=$ Antepartum eclampsia, $\mathrm{PPE}=$ Postpartum eclampsia

It shows the patient characteristics of both the groups, age distribution, type of eclampsia, antenatal booking and gravid status, period of gestation, BMI, systolic and diastolic BP status; all were comparable in both the 
groups. The commonest gestation when eclampsia/imminent eclampsia occurred was at 32-37 weeks $(64.70 \% / 51.2 \%)$. Most common premonitory symptom \& sign in the patients of severe preeclampsia was blurring of vision present in $12.5 \%$ patients in IV and $16.66 \%$ patients in IM. The admission to delivery interval was approximately $13.735 \pm 7$ hours in IM group and $13.06 \pm 5.9$ hours in IV group. The mean dose of magnesium sulfate given in IV and IM group was $63.27 \pm$ $16.62 \mathrm{gm}$ and $65.93 \pm 18.12 \mathrm{gm}$, respectively (statistically not significant). As shown in Table 4
$68.29 \%$ of patients delivered by vaginal route in IV and $75.6 \%$ in IM group.

Signs of impending toxicity as in Table 2 were found more in IM group $16 / 41(39.02 \%)$ as compared to IV group 5/41 (12.19\%). Loss of patellar reflex was present in 10/41 (24.39\%) subjects of IM group and only in 3/41 $(7.31 \%)$ in IV group and this was statistically significant. $\mathrm{P}=(0.034)$. Rest of the signs of impending toxicity (like oliguria, $\mathrm{RR}<16 / \mathrm{min}$, local site complications) though more in IM group were statistically insignificant.

Table 2: Signs of magnesium toxicity.

\begin{tabular}{|c|c|c|c|c|c|c|c|c|c|c|c|c|c|c|}
\hline \multirow{3}{*}{ Signs } & \multicolumn{6}{|c|}{ IM group $(n=41)$} & \multicolumn{6}{|c|}{ IV group $(n=41)$} & \multicolumn{2}{|c|}{$\begin{array}{l}\text { Chi-square \& } \\
\text { P value (IM vs. } \\
\text { IV group) }\end{array}$} \\
\hline & \multicolumn{2}{|c|}{$E(n=17)$} & \multicolumn{2}{|c|}{$\begin{array}{l}\text { SPE } \\
(n=24)\end{array}$} & \multicolumn{2}{|c|}{$\begin{array}{l}\text { Total } \\
(n=41)\end{array}$} & \multicolumn{2}{|c|}{$E(n=17)$} & \multicolumn{2}{|c|}{$\begin{array}{l}\text { SPE } \\
(n=24)\end{array}$} & \multicolumn{2}{|c|}{$\begin{array}{l}\text { Total } \\
(n=41)\end{array}$} & \multirow{2}{*}{$x^{2}$} & \multirow{2}{*}{$\mathbf{P}$} \\
\hline & No. & $\%$ & No. & $\%$ & No. & $\%$ & No. & $\%$ & No. & $\%$ & No. & $\%$ & & \\
\hline Loss of patellar reflex & 2 & 11.8 & 8 & 33.3 & 10 & 24.4 & 2 & 11.8 & 1 & 4.2 & 3 & 7.3 & 4.479 & $0.034 *$ \\
\hline U/O decreased & 2 & 11.8 & 2 & 8.3 & 4 & 9.8 & 1 & 5.9 & 1 & 4.2 & 2 & 4.9 & 0.719 & 0.396 \\
\hline $\mathrm{RR}<16 /$ minute & 1 & 5.9 & 0 & 0.0 & 1 & 2.4 & 0 & 0.0 & 0 & 0.0 & 0 & 0.0 & 1.012 & 0.314 \\
\hline Local site complication & 0 & 0.0 & 1 & 4.2 & 1 & 2.4 & 0 & 0.0 & 0 & 0.0 & 0 & 0.0 & 1.012 & 0.314 \\
\hline
\end{tabular}

$\mathrm{U} / \mathrm{O}=$ Urine output, $\mathrm{RR}=$ Respiratory rate

Treatment complications are shown in Table 3. We defined recurrence of convulsions if it occurred 30 minutes after the loading dose. Recurrence of convulsion was found in $1(5.88 \%)$ patient in IV and $1(5.88 \%)$ patients in IM group. Each episode was treated with additional 2 gram of magnesium sulfate. In this study none of the patient with severe preeclampsia developed convulsion after the therapy. Obstetric complications as shown in Table 3 during labour and delivery (Like atonic PPH and abruption and RD) were $14.63 \%$ and $17.07 \%$ in IV and IM group respectively (statistically not significant
$\mathrm{P}=0.762$ ). Other complications (Acute renal failure, pulmonary edema, thrombocytopenia) were $(9.75 \%)$ and $(17.07 \%)$ in IV and IM group respectively. 1/41 (2.43\%) patient expired in IM group but there was no mortality in IV group. Table 5 shows a higher Perinatal mortality in IM group when compared to IV (17.07\% in IV $13.95 \%$ in IM) but it was insignificant. Mean baby weight at birth was almost similar in both group; $(2.34 \pm 6 \mathrm{~kg})$ in IV and $2.31 \pm 0.75 \mathrm{~kg}$ in IM group. APGAR Scores and rate of admissions in neonatal intensive care unit were found to be comparable in both the groups.

Table 3: Signs of magnesium toxicity.

\begin{tabular}{|c|c|c|c|c|c|c|c|c|c|c|c|c|c|c|}
\hline \multirow{3}{*}{ Complications } & \multicolumn{6}{|c|}{ IM group $(n=41)$} & \multicolumn{6}{|c|}{ IV group $(n=41)$} & \multicolumn{2}{|c|}{$\begin{array}{l}\text { Chi-square } \& \\
\text { P value (IM } \\
\text { vs. IV group) }\end{array}$} \\
\hline & \multicolumn{2}{|c|}{$E(n=17)$} & \multicolumn{2}{|c|}{$\begin{array}{l}\text { SPE } \\
(n=24)\end{array}$} & \multicolumn{2}{|c|}{$\begin{array}{l}\text { Total } \\
(n=41)\end{array}$} & \multicolumn{2}{|c|}{$E(n=17)$} & \multicolumn{2}{|c|}{$\begin{array}{l}\text { SPE } \\
(n=24)\end{array}$} & \multicolumn{2}{|c|}{$\begin{array}{l}\text { Total } \\
(n=41)\end{array}$} & \multirow[t]{2}{*}{$x^{2}$} & \multirow{2}{*}{$\mathbf{P}$} \\
\hline & No. & $\%$ & No. & $\%$ & No. & $\%$ & No. & $\%$ & No. & $\%$ & No. & $\%$ & & \\
\hline $\begin{array}{l}\text { Complication during } \\
\text { labour/delivery } \\
(\mathrm{PPH}, \text { abruption, } \mathrm{R})\end{array}$ & 2 & 11.8 & 5 & 20.8 & 7 & 17.1 & 4 & 23.5 & 2 & 8.3 & 6 & 14.6 & 0.091 & 0.762 \\
\hline $\begin{array}{l}\text { Other complications } \\
\text { (like TCP, ARF, PE) }\end{array}$ & 4 & 23.5 & 3 & 12.5 & 7 & 17.1 & 3 & 17.6 & 1 & 4.2 & 4 & 9.8 & 0.945 & 0.331 \\
\hline Maternal ICU admission & 1 & & & & & & & 0 & & & & & 1.012 & 0.314 \\
\hline Maternal morality & 1 & & & & & & & 0 & & & & & 1.012 & 0.314 \\
\hline Recurrence of fits & 1 & & & & & & & 1 & & & & & 0.00 & 1.00 \\
\hline
\end{tabular}

$\mathrm{PPH}=$ Post-partum haemorrhage, $\mathrm{RD}=$ Respiratory depression, $\mathrm{TCP}=$ Thrombocytopenia, $\mathrm{ARF}=$ Acute renal failure, $\mathrm{PE}=\mathrm{Pulmonary}$ oedema, E = Eclampsia, SPE = Severe Preeclampsia, ICU= Intensive care unit 
Table 4: Mode of delivery.

\begin{tabular}{|c|c|c|c|c|c|c|c|c|c|c|c|c|c|c|}
\hline \multirow{3}{*}{$\begin{array}{l}\text { Mode of } \\
\text { delivery }\end{array}$} & \multicolumn{4}{|c|}{ IM group } & & & \multicolumn{6}{|c|}{ IV group } & \multicolumn{2}{|c|}{$\begin{array}{l}\text { Chi-square \& } \mathbf{P} \\
\text { value (Control } \\
\text { vs. study group) }\end{array}$} \\
\hline & \multicolumn{2}{|c|}{$E(n=17)$} & \multicolumn{2}{|c|}{$\begin{array}{l}\text { SPE } \\
(n=24)\end{array}$} & \multicolumn{2}{|c|}{$\begin{array}{l}\text { Total } \\
(n=41)\end{array}$} & \multicolumn{2}{|c|}{$E(n=17)$} & \multicolumn{2}{|c|}{$\begin{array}{l}\text { SPE } \\
(n=24)\end{array}$} & \multicolumn{2}{|c|}{$\begin{array}{l}\text { Total } \\
(n=41)\end{array}$} & \multirow{2}{*}{$\chi^{2}$} & \multirow[t]{2}{*}{$\mathbf{P}$} \\
\hline & No. & $\%$ & No. & $\%$ & No. & $\%$ & No. & $\%$ & No. & $\%$ & No. & $\%$ & & \\
\hline Vaginal & 13 & 76.5 & 18 & 75.0 & 31 & 75.6 & 11 & 64.7 & 17 & 70.8 & 28 & 68.3 & \multirow{2}{*}{0.544} & \multirow{2}{*}{0.461} \\
\hline LSCS* & 4 & 23.5 & 6 & 25.0 & 10 & 24.4 & 6 & 35.3 & 7 & 29.2 & 13 & 31.7 & & \\
\hline
\end{tabular}

*Lower segment caesarean section

Table 5: Perinatal outcome.

\begin{tabular}{|lllll|}
\hline Outcome & $\begin{array}{l}\text { IM group } \\
(\mathrm{n}=41)\end{array}$ & $\begin{array}{l}\text { IV group } \\
(\mathrm{n}=\mathbf{4 3})\end{array}$ & $\chi^{2}$ & $\mathrm{P}$ \\
\hline $\begin{array}{l}\text { Alive } \\
\text { (along with } 4 \\
\text { twins }) / \mathrm{IUD}\end{array}$ & $34 / 7$ & $37 / 6$ & 0.734 & 0.391 \\
\hline Baby weight & $2.31 \pm 0.75$ & $2.34 \pm 6.0$ & 0.204 & 0.839 \\
\hline $\begin{array}{l}\text { NICU } \\
\text { admission }\end{array}$ & $9(\mathrm{n}=32)$ & $10(\mathrm{n}=35)$ & 0.0037 & 0.951 \\
\hline $\begin{array}{l}\text { APGAR score } \\
<7 \text { at 5 minute }\end{array}$ & 24 & 25 & 0.0968 & 0.751 \\
\hline
\end{tabular}

IUD=Intra uterine death, NICU=Neonatal intensive care unit

\section{DISCUSSION}

The use of $\mathrm{MgSO}_{4}$ for seizure control and prophylaxis has been shown to be efficacious in women with eclampsia and severe preeclampsia. The routine use of seizure prophylaxis in women with mild preeclampsia has never been supported by evidence. It has been found that the routine use of magnesium sulfate therapy is not without complications. Maternal morbidity and mortality can occur because of magnesium overdose and toxicity, which can be prevented by giving magnesium sulfate at controlled rate and by close monitoring of the patient and this can be accomplished by IV continuous $\mathrm{MgSO}_{4}$ regimen. While most of the health centers in world administer $\mathrm{MgSO}_{4}$ by continuous infusion since the IV route for $\mathrm{MgSO}_{4}$ administration has many advantage over $\mathrm{IM} \mathrm{MgSO}_{4}$ but, in India most medical centers prefer IM administration as described by Pritchard because most of the sets ups have poor resources and giving IV magnesium sulfate is not practical due to non-availability of infusion sets, too busy nursing staff, taking sample for serum magnesium level at frequent interval is not cost effective. In this study both the route for $\mathrm{MgSO}_{4}$ administration were compared and magnesium toxicity was measured by clinical parameters

Maximum patients in both the IV and IM group were of age group 20-30 years. In IV group 36/41 (87.80\%) and in IM group 39/41 (95.12\%) were of this age group. The youngest one was 19 years age \& oldest was 40 years old. Mean age in IV group was $26.02 \pm 3.984$ and in IM was $25.4 \pm 3.969(\mathrm{P}=0.525)$. Difference was not statistically significant. $(\mathrm{P}=0.934)$. Our findings were similar to Singh VK and Pandey K et al. (1992); ${ }^{8}$ in their series of 80 patients with eclampsia they found that the age ranged from 15-40 years with mean age 26.5 years. Sibai ${ }^{9}$ reported mean age 18.5 years. $33(80.5 \%)$ in IV and 36 $(87.8 \%)$ in IM group belonged to rural background. Most of the cases of eclampsia $(79.41 \%)$ and severe preeclampsia $(87.5 \%)$ belonged to rural background. There were 7 (17.07\%) booked cases in IV group while 5 $(12.19 \%)$ in IM group. Mostly there were unbooked cases $(85.3 \%)$, similar percentage of unbooked eclampsia were reported by Agarwal ${ }^{10}$ (1983) 92\%, Sahu L ${ }^{11}$ (2012) in range of $92 \%-84 \%$. Statistically, the group were matched parity wise and gestational age wise $(\mathrm{P}>0.05) .26$ (63.41\%) were nulliparous in IV group and 24 (58.53\%) in IM group. Difference was not statistically significant $(\mathrm{P}=0.651)$. Majority the cases of eclampsia $(64.70 \%)$ and severe preeclampsia $(58.33 \%)$ were nulliparous. Ekel $^{7}$ (2005) reported it to be $89 \%$ while Seth et al. ${ }^{2}$ (2010) found incidence of eclampsia in primigravida to be $74.2 \%$. Mean gestational age of IV group was $36.11 \pm$ 2.93 weeks while IM group was $35.31 \pm 3.11$ weeks. $52.94 \%$ in IV group of eclampsia and $76.47 \%$ in IM group eclampsia were admitted at gestational age 32-37 weeks. Also in severe preeclampsia most were of gestational age $32-37$ weeks (51.21\%). Duration of gestation in eclampsia varies from in different studies. Seth et al. ${ }^{2}$ found (31.8\%) patients between 32-36 weeks.

30 patients $(88.23 \%)$ of eclampsia had antepartum eclampsia / intrapartum eclampsia while $4(11.76 \%)$ had post-partum eclampsia. In the study by Bangal et al., ${ }^{12}$ $60 \%$ of cases had antepartum, $28 \%$ cases had intrapartum and $12 \%$ cases had postpartum eclampsia. The mean systolic blood pressure was $174.44 \pm 12.97 \mathrm{~mm}$ of $\mathrm{Hg}$ in IM group while in IV group it was $173.22 \pm 14.81 \mathrm{~mm}$ of Hg. Similarly, mean diastolic blood pressure was 110.98 \pm 10.48 and $110.24 \pm 7.58 \mathrm{~mm}$ of $\mathrm{Hg}$ in IM and IV group respectively. Coetzee EJ et al. ${ }^{13}$ (822 patient of severe preeclampsia) found mean systolic blood pressure 173 and diastolic 116.

Both the group had $1 / 17$ (5.88\%) cases each with recurrence of convulsion after the loading dose. The difference between the two groups was statistically insignificant $(\mathrm{P}=1)$. Pritchard ${ }^{6}$ and $\mathrm{Sibai}^{14}$ have reported recurrence rates of $11 \%$ and $16 \%$ respectively. The 
recurrence rate reported in collaborative eclampsia trial ${ }^{15}$ using Pritchard's regimen ranged between 5.7 and 13.2\%. There was no occurrence of convulsion in any subject with severe preeclampsia. Coetzee et al. ${ }^{13}$ found occurrence of convulsion rate of $0.3 \%$ in severe eclampsia group after receiving IV magnesium sulfate.

Chinayon $\mathrm{P}^{16}(1998)$ and Ekele ${ }^{7}$ (2005) suggested that, clinical assessment of knee jerk, respirations and urine output is adequate to monitor maternal magnesium toxicity without the need to determine actual maternal serum levels. In this study we also evaluated the impending signs of toxicity clinically; loss of patellar reflex, which was higher in IM 10/41 (24.39\%) as compared to IV 3/41(7.31) group, which was significant, $(\mathrm{P}=0.034)$. Oliguria was less in IV than IM group $2.43 \%$ vs. $7.31 \%(P=0.396)$. Local site abscess was seen in 1 case of eclampsia IM group which was managed conservatively. No patient in IV group had respiratory depression, or any local site complication such as phlebitis. Overall signs of impending toxicity were more common in IM group compared to IV group (39.02\% IM/12.19\% IV) but it was not statistically significant. Chissell $\mathrm{S}^{17}$ (1994) described magnesium toxicity in $1 / 8$ $(12.5 \%)$ cases of IV group and none in IM group.

Table 6: Comparison of complications with study of Sardesai et al. ${ }^{18}$ (2003).

\begin{tabular}{|llll|}
\hline Study & Complication & IV & IM \\
\hline \multirow{3}{*}{$\begin{array}{l}\text { Sardesai } \\
\text { et al. }\end{array}$} & Cerebral haemorrhage & 3 & - \\
\cline { 2 - 4 } 2003 & Pulmonary oedema & 4 & - \\
\cline { 2 - 4 } & HELLP syndrome & 4 & 1 \\
\cline { 2 - 4 } & ARF & 4 & 1 \\
\cline { 2 - 4 } & PPH & - & 1 \\
\cline { 2 - 4 } Our & DIC & 15 & 3 \\
\cline { 2 - 4 } study & Abruptio & $3(7.31 \%)$ & $3(7.31 \%)$ \\
\cline { 2 - 4 } & Pulmonary oedema & $1(2.43 \%)$ & 0 \\
\cline { 2 - 4 } & Thrombocytopenia & $4(9.75 \%)$ & $4(9.75 \%)$ \\
\cline { 2 - 4 } & ARF & 0 & $3(7.31 \%)$ \\
\cline { 2 - 4 } & PPH & 0 & $3(7.31 \%)$ \\
\hline
\end{tabular}

HELLP $=$ Hemolysis elevated liver enzymes low platelet count, $\mathrm{PPH}=$ Post-partum haemorrhage, $\mathrm{RD}=$ Respiratory depression, $\mathrm{ARF}=$ Acute renal failure, DIC $=$ Disseminated intravascular coagulopathy

Common complications observed in our patients were abruptio atonic-PPH, thrombocytopenia, ARF, pulmonary-oedema. There were $3 / 41$ (7.31\%) in IV and similar number $3 / 41(7.35 \%)$ in IM group who had PPH. Abruptio was found in $3 / 41(7.31 \%)$ in IV and $3 / 41$ (7.31\%) in IM group. Thrombocytopenia was seen equally $4 / 41(9.57 \%)$ both group. $3 / 41$ (7.31\%) patients had ARF in IM group but none in IV group.1/41(2.43\%) patient had pulmonary oedema in IV group no such complication was present in IM group. None of the patient in either group had bed sores, injection site cellulitis, hematuria, post-partum psycho. In our study $24.39 \%$ in IV group and $34.14 \%$ in IM group had complications during labour and delivery which was not statistically significant. Comparison of complications with study of Sardesai et al. ${ }^{18}$ (2003) is shown in Table 6.

One patient $(2.43 \%)$ of eclampsia expired after respiratory depression, she was shifted to ICU but expired despite of intensive management. No such were found in IV group. Thus maternal mortality rate was $1.22 \%$. Chowdhary et al. ${ }^{19}$ reported maternal mortality rate of $5 \%$ in the IM and $3.3 \%$ in the IV groups. Mode of delivery in most of the cases was by vaginal route-28/41 patients $(68.29 \%)$ in IV group \& $31 / 41$ patients $(75.60 \%)$ in IM group. In eclampsia (17 each of IM and IV group) patients more common mode of delivery was by vaginal route in 24/34 (70.58\%), LSCS was done in $10(29.41 \%)$ women of eclampsia. Also among severe preeclampsia (24 each of IM and IV group) commoner route of delivery was vaginal route $35 / 48(72.91 \%)$ and by LSCS in $13 / 48(27.08 \%)$. Cesarean section rate in collaborative eclampsia trial $^{15}$ was 66 to $72 \%$ using standard Pritchard's regimen. In study of Chissell $\mathrm{S}^{17}$ caesarean section rate was $4 / 8$ in IV group and $3 / 9$ in IM group respectively.

Neonatal outcome depends on severity of associated intrauterine growth retardation (IUGR), gestational age, birth weight and the level of facilities in NICU. There were 34 live deliveries in IM group as compared to 37 in IV group and there were no still births. Statistically, there was no significant difference in two groups. Perinatal mortality was $7 / 41(13.95 \%)$ in IV group and $6 / 43(17.07 \%)$ in IM group. Overall perinatal mortality in our study was $15.47 \%$. Sardesai, ${ }^{18}$ Pritchard $^{6}$ showed $20.22 \%$, 33.83\% perinatal mortality respectively. Collaborative eclampsia trial ${ }^{15}$ using standard dose regimen found perinatal mortality rate of $24-26 \%$ and birth asphyxia of $44-48 \%$ in eclampsia. Chissell $\mathrm{S}^{17}$ showed $1 / 8$ and $1 / 9$ stillbirth in both IV and IM severe eclampsia group respectively. It was seen that subjects in IM group had no significant difference as regard babies with low APGAR score as compared to subjects in IV group $(\mathrm{P}=0.751)$. In our study there were needs of NICU admission in 10 live births $(14.92 \%)$ in IV group 9 $(13.43 \%)$ in IM group.

In the study of Shela Noor ${ }^{20}$ et al. using Pritchard regimen, $3.77 \%$ of eclamptic and $10 \%$ of severe preeclampsia babies required nursery admission. The mean baby weight in IM group was $2.31 \pm 0.75 \mathrm{~kg}$ as compared to $2.34 \pm 6 \mathrm{~kg}$ in IV group, thus showing no significant difference between two groups $(\mathrm{P}=0.839)$. Amongst patients of eclampsia $35.29 \%$ of live babies were of birth weight $\geq 2.5 \mathrm{~kg}$ and among severe preeclampsia $45.83 \%$ of live babies were of birth weight $\geq 2.5$.

\section{CONCLUSION}

We can conclude from above study that Pritchard regimen and IV continuous magnesium sulfate regimen 
are equally effective in terms of control \& prevention of recurrence of convulsions. Signs of magnesium toxicity (except for loss of patellar reflex which was more in IM group) was almost similar in both regimen. Overall perinatal outcome was equal in both the groups. IM regimen has the disadvantage of painful injections, but it has the advantage of great convenience. In settings where pumps for IV infusion are not readily available and, the nursing staff may be too busy to provide the continuous monitoring required. The IM route, where a dose is only given; once the reflexes, respiration and urine output have been checked, is likely to be safer. There is no significant difference in these two regimens, IM dose can be given preferentially where frequent monitoring of magnesium level is not practical.

\section{Funding: No funding sources}

Conflict of interest: None declared

Ethical approval: The study was approved by the institutional ethics committee

\section{REFERENCES}

1. Bhargava A, Pant R, Chutani I, Singh SR. Accelerated recovery from eclampsia. J Obstet Gynecol India. 2006;56:402-5.

2. Seth S, Nagrath A, Singh DK. Comparison of low dose, single loading dose and standard Pritchard regimen of magnesium sulphate in ante-partum eclampsia. Anatol J Obstet Gynecol. 2010;1(1):1-4.

3. World Health Organization. Maternal mortality: fact sheet No348", 2014. Available at: http://www.who.int/mediacentre/factsheets/fs348/en/ . Accessed 20 June 2014.

4. Mackay AP, Berg CJ, Atrash HK. Pregnancy-related mortality from preeclampsia and eclampsia. Obstet Gynecol. 2001;97:533-8.

5. No Author. Which anticonvulsant for women with eclampsia? Evidence from the Collaborative Eclampsia Trial. Lancet. 1995;345(8963):1455-63.

6. Pritchard JA, Cunningham, FG Pritchard SA. The parkland memorial hospital protocol for treatment of eclampsia evaluation of 245 cases. Am J Obstet Gynecol. 1984:148(7);951-63.

7. Ekele BA, Badung SL. Is serum magnesium estimate necessary in patients with eclampsia on magnesium sulphate? Afr J Reprod Health. 2005 Apr;9(1):12832

8. Singh VK, Pandey K. Study of 80 patients with eclampsia. J Obstet Gynaecol India. 1992;43(4):54761.

9. Sibai BM, Graham JM, McCubbin JH. A comparison of IV and IM magnesium sulphate regimens in preeclampsia. Am J Obstet Gynecol. 1984;150:72833.

10. Agarwal S, Dhall K, Bhatia K. Epidemiologic IV of eclampsia. J Obstet Gynaecol India. 1983;33:83.

11. Latika Sahu, Shubhra Singh, Anjali Tempe, B. C. Koner. A randomized comparative study between low-dose magnesium sulphate and standard dose regimen for management of eclampsia. Int J Reprod Contracept Obstet Gynecol. 2014;3(1):79-86.

12. Bangal VB, Purushottam A. Giri, Satyajit P. Gavhane. A study to compare the efficacy of low dose magnesium sulphate regime with Pritchard regime in eclampsia. Int $\mathrm{J}$ Biomed Adv Res. 2012;3(1):53-7.

13. Coetzee EJ, Dommisse J, Anthony JA. Randomized controlled trial of IV magnesium sulphate versus placebo in the management of women with severe preeclampsia. S Afr Med J. 1994 Sep;84(9):607-10.

14. Sibai BM. Magnesium sulfate is the ideal anticonvulsant in preeclampsia - eclampsia. Am J Obstet Gynecol. 1990;162(5):1141-5.

15. Duley L. The Eclampsia Trial collaborative Group. Which anticonvulsant for women with eclampsia? Evidence from the Collaborative Eclampsia trial. Lancet. 1995;345:1455-63.

16. Chinayon P. Clinical management and outcome of eclampsia at Rajavithi Hospital. J Med Assoc Thai. 1998;81(8):579-85.

17. Chissell S, Botha JH, Moodley J, McFadyen L. IV and IM magnesium sulphate regimens in severe preeclampsia. S Afr Med J. 1994 Sep;84(9):607-10.

18. Sardesai S, Maira S, Patil A. Low dose magnesium sulphate therapy for eclampsia and imminent eclampsia - regimen tailored for Indian women. J Obstet Gynecol India. 2003;53(6):546-50.

19. Joydeb Roy Chowdhury, Snehamay Chaudhuri, Nabendu Bhattacharyya, Pranab Kumar Biswas, Madhabi Panpalia. Comparison of IM magnesium sulfate with low dose IV magnesium sulfate regimen for treatment of eclampsia. J Obstet Gynaecol Res. 2009;35(1):119-25.

20. Shehla Noor, Mussarat Halimi, Nasreen Ruby Faiz, Fouzia Gull, Nasreen Akbar. Magnesium sulphate in the prophylaxis and treatment of eclampsia. J Ayub Med Coll Abbottabad. 2004 Apr-Jun;16(2):50-4.

DOI: 10.5455/2320-1770.ijrcog20150235

Cite this article as: Kanti V, Gupta A, Seth S, Bajaj M, Kumar S, Singh M. Comparison between IM and IV regimen of magnesium sulfate in management of severe preeclampsia and eclampsia. Int J Reprod Contracept Obstet Gynecol 2015;4:195-201. 